\title{
Changes in Serum Thyroid Hormone Levels in Newborn Calves as a Diagnostic Index of Endemic Goiter
}

\author{
Kenichi TAKAHASHI ${ }^{1}$, Eiji TAKAHASHI ${ }^{1)}$, Rio John T. DUCUSIN ${ }^{1)}$, Shigeyuki TANABE ${ }^{1)}$, Yuji UZUKA ${ }^{1)}$ and \\ Takao SARASHINA ${ }^{1) *}$ \\ ${ }^{1)}$ Department of Veterinary Internal Medicine, Obihiro University of Agriculture and Veterinary Medicine, 11 Nishi-2, Inada-cho, Obihiro \\ 080-8555, Japan
}

(Received 8 May 2000/Accepted 10 October 2000)

ABSTRACT. Maximum serum thyroxine $\left(\mathrm{T}_{4}\right)$ and triiodothyronine $\left(\mathrm{T}_{3}\right)$ levels of healthy calves were seen at 1 day after birth, and thereafter rapidly decreased until 5 days after birth. They stabilized until 2 weeks after birth, then gradually decreased until 4 weeks after birth. Serum $\mathrm{T}_{4}$ levels of calves with endemic goiter tended to be lower than those of healthy ones, but showed similar levels to those of adult cows. $T_{3}$ levels of calves with goiter were similar to those of healthy ones, but showed higher variation. $T_{4} / T_{3}$ ratio of calves with goiter were significantly lower than those of healthy ones and adult cows. While individual levels of serum $\mathrm{T}_{4}$ and $\mathrm{T}_{3}$ at just after birth could not be considered as a diagnostic index, the $T_{4} / T_{3}$ ratio could be adopted as a diagnostic index of endemic goiter.

KEY WORDS: calf, endemic goiter, $\mathrm{T}_{3} / \mathrm{T}_{4}$ ratio.

The histopathological changes of an enlarged thyroid gland together with other evidence of hypothyroidism are necessary to diagnose endemic goiter in newborn calves [6, $9,11]$. However, since the energy metabolic rate is higher in newborn calves, thyroid hormone levels may be more variable just after birth. In this paper, the thyroid hormone levels of calves with goiter were compared with those of healthy calves and adult cows to investigate a possible diagnostic index of endemic goiter in calves.

Six healthy Holstein calves were examined. Newborn Holstein calves with goiter $(n=34)$ found at 3 farms in the Tokachi district in Hokkaido were also examined. The diagnosis of endemic goiter was based on histopathological findings of enlarged thyroid glands. The blood of healthy calves was collected from the jugular vein at the following times: just after birth, 1, 3, 5, 7 days after birth, 2, 3, 4 weeks after birth, and 2 months after birth. The blood of calves with endemic goiter was collected just after birth $(n=13), 1(n=8)$ and $3(n=5)$ days after birth, and at $2(n=4)$ and $4(n=4)$ weeks after birth. As a control, the blood of healthy 18-21 month-old adult cows $(n=6)$ was also examined. Serum was separated quickly from collected blood then frozen at $-20^{\circ} \mathrm{C}$ until determination of the thyroid hormone levels.

Serum thyroxine $\left(T_{4}\right)$ and serum triiodothyronine $\left(T_{3}\right)$ of healthy calves, calves with goiter and healthy adult cows were determined by the RIA method (SPAC $\mathrm{T}_{4}$ RIA Kit and SPAC $T_{3}$ RIA Kit, Daiichi RI institute) and the $T_{4} / T_{3}$ ratio was calculated. Differences of thyroid hormone levels among healthy calves, calves with goiter and healthy adult cows were considered significant if $\mathrm{p}$ values were $<0.05$ or $<0.01$ by Student's $t$ test.

\footnotetext{
* Correspondence to: Sarashina, T., Department of Veterinary Internal Medicine, Obihiro University of Agriculture and Veterinary Medicine, 11 Nishi-2, Inada-cho, Obihiro 080-8555, Japan.
}

Figure 1 shows the changes in serum levels of thyroxine $\left(T_{4}\right)$, triiodothyronine $\left(T_{3}\right)$ and the $T_{4} / T_{3}$ ratio in healthy calves and calves with goiter. These were compared with those of adult cows. Serum $\mathrm{T}_{4}$ levels of healthy calves until 7 days after birth were significantly $(p<0.01)$ higher than those of adult cows, and showed the maximum levels at 1 day after birth. Thereafter, they decreased rapidly until 5 days after birth. The levels at 2 weeks after birth were significantly $(p<0.05)$ higher than those of adult cows but gradually decreased to levels not significantly different with those of adult cows until 4 weeks after birth, thereafter showing stable levels until 2 months. Serum $T_{3}$ levels of healthy calves followed the same pattern as $T_{4}$ levels, and compared with $\mathrm{T}_{3}$ levels of adult cows, were significantly higher $(\mathrm{p}<0.01$ or $\mathrm{p}<0.05)$ until 3 weeks after birth. Thereafter, they decreased gradually to a minimum level which was the same as that of adult cows, and stabilized until 2 months after birth. The $\mathrm{T}_{4} / \mathrm{T}_{3}$ ratio of healthy calves tended to be higher than that of adult cows at birth, but except for those at 3 and 4 weeks after birth were significantly $(\mathrm{p}<0.01$ or $\mathrm{p}<0.05)$ lower than those of adult cows. On the other hand, serum $\mathrm{T}_{4}$ levels of calves with goiter tended to be lower than those of healthy calves from birth to 2 weeks after birth. There was no significant difference between serum $\mathrm{T}_{4}$ levels of calves with goiter and adult cows. Serum $\mathrm{T}_{3}$ levels of calves with goiter were significantly $(\mathrm{p}<0.01)$ higher than those of adult cows, but showed higher variation than those of healthy ones. The $\mathrm{T}_{4} / \mathrm{T}_{3}$ ratios of calves with goiter were significantly $(\mathrm{p}<0.01$ or $\mathrm{p}<0.05)$ lower than those of healthy ones and adult cows from 0 day to 4 weeks after birth. Figure 2 is a more detailed presentation of the serum levels of $T_{4}, T_{3}$ and the $T_{4} / T_{3}$ ratio in 1 day old healthy calves, 1 day old calves with goiter, and 18-21 months old adult cows. Serum $\mathrm{T}_{4}$ levels in calves with goiter were significantly $(\mathrm{p}<0.01)$ lower than those of healthy 

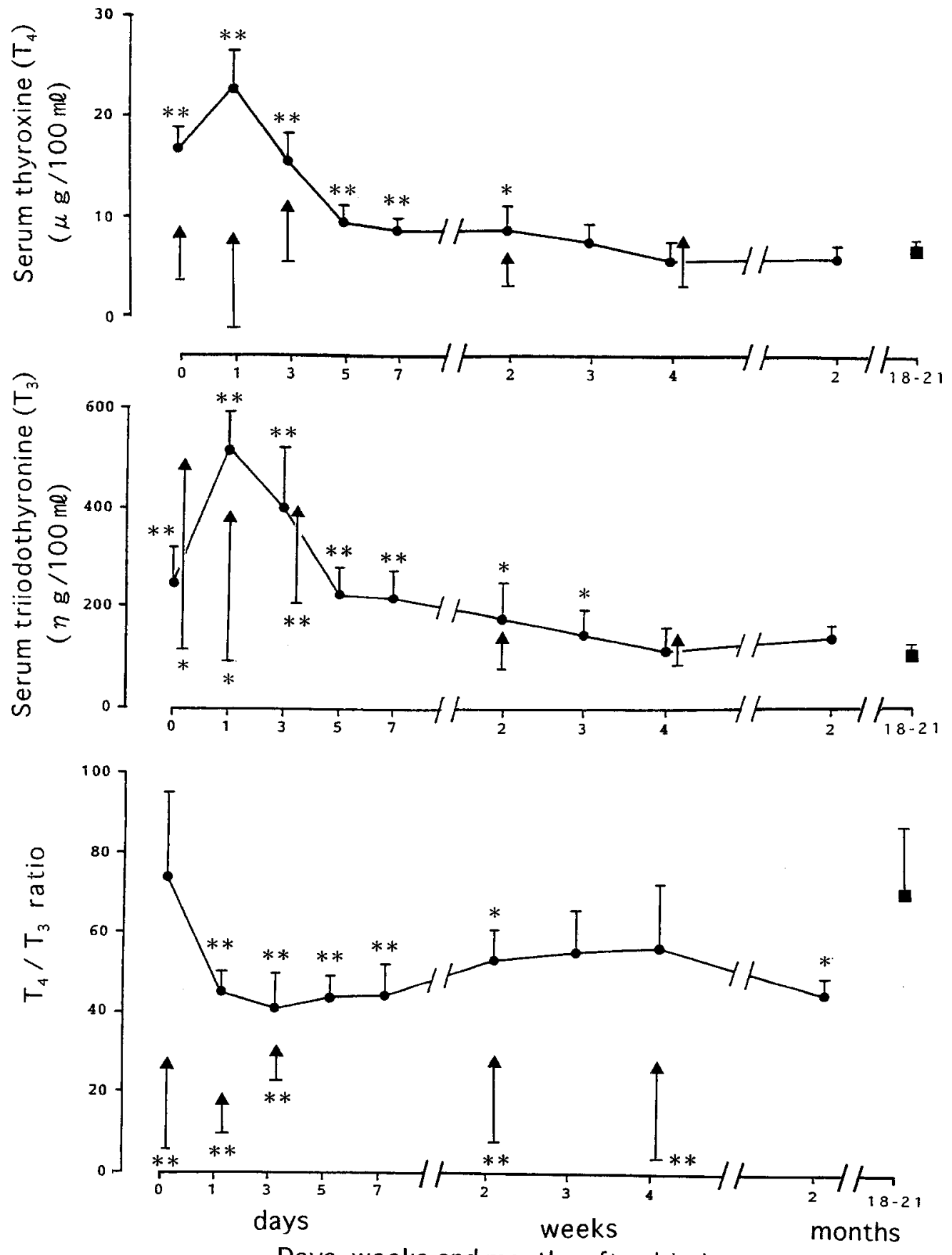

Days, weeks and months after birth

Fig. 1. Changes in serum levels of thyroxine $\left(T_{4}\right)$, triiodothyronine $\left(T_{3}\right)$ and $T_{4} / T_{3}$ ratio in healthy calves $(\mathbf{O})$ and calves with goiter $(\boldsymbol{\Delta})$. The values were compared with the levels in adult cows $(\boldsymbol{\square})$. Significant difference $(* *$ : $\mathrm{p}<0.01, *: \mathrm{p}<0.05)$ was seen between calves and adult cows.

ones and adult cows. Serum $\mathrm{T}_{3}$ levels of calves with goiter were significantly $(\mathrm{p}<0.05)$ lower than those of healthy ones, but were significantly $(\mathrm{p}<0.01)$ higher than those of adult cows. The $T_{4} / T_{3}$ ratio of calves with goiter was significantly $(p<0.01)$ lower than those of healthy calves and adult cows.

The thyroid glands of the calves with goiter enlarged markedly. Thirteen had golfball-sized $(4 \mathrm{~cm}), 10$ had eggsized $(6 \mathrm{~cm}), 6$ had fist-sized $(9 \mathrm{~cm})$ and 5 had softball-sized $(10 \mathrm{~cm})$ enlargements. In the histopathological findings of 

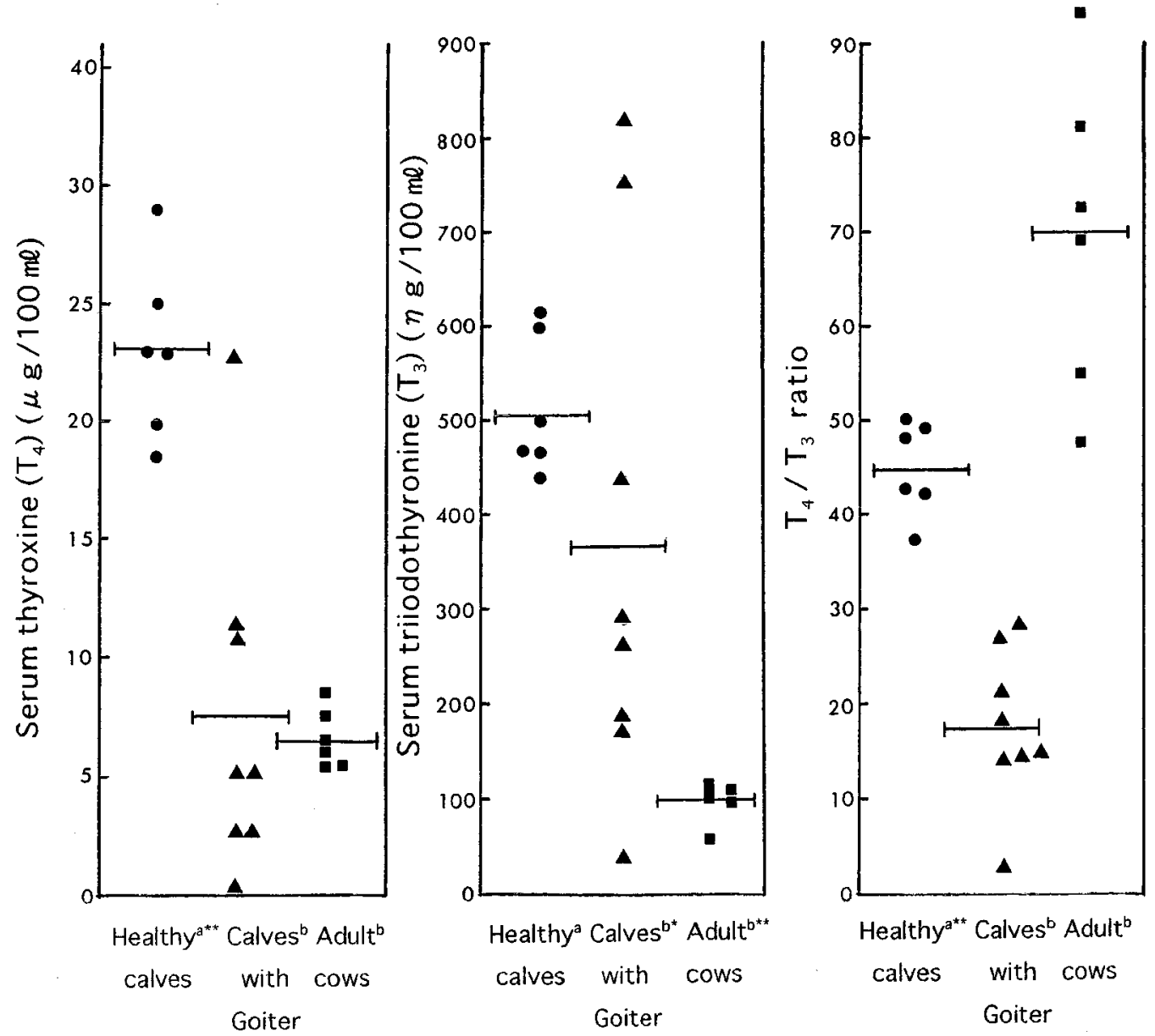

Fig. 2. Serum levels of thyroxine $\left(T_{4}\right)$, triiodothyronine $\left(T_{3}\right)$ and $T_{4} / T_{3}$ ratio in 1 day old healthy calves $(\boldsymbol{O}), 1$ day old calves with goiter $(\boldsymbol{\Delta})$ and 18-21 months old adult cows $(\boldsymbol{\square})$. Horizontal lines represent the mean levels of each group. Asterisks (**: $\mathrm{p}<0.01, *: \mathrm{p}<0.05)$ denote significant differences from adult cows.

the biopsy materials of the thyroid glands diffuse hyperplastic goiter was evident. The main clinical sign in 17 calves was weakness and they died within 3 days. Marked abnormality was not evident in the other calves.

Serum $T_{4}$ and $T_{3}$ levels of the healthy calves were significantly higher at birth than those of adult cows. Maximum levels were seen at 1 day after birth, and thereafter decreased to the levels of adult cows [5] at 4 weeks after birth. These results are similar to the findings of previous studies $[2,8]$. In cattle, iodide trapping in the thyroid gland of the fetus begins at about 60 days [4]. Blood $\mathrm{T}_{4}$ levels begin to increase in the middle fetal stage, and increase until twice the level of the dams in the late fetal stage [3]. With regard to $\mathrm{T}_{3}$ levels, these are low in the fetal stage, but increase until they reach the level of the dams at birth [13]. This phenomenon is thought to be caused by the rise of deiodination from $T_{4}$ to $T_{3}$ in peripheral tissues [13]. In cattle [2], sheep [7] and swine [12], TSH is released actively and $\mathrm{T}_{4}$ and $\mathrm{T}_{3}$ levels increase until $24-48 \mathrm{hr}$ after birth. This stimulation is transmitted by TRH in the hypothalamus, leading to increased secretion of $\mathrm{TSH}$, and subsequently increased secretion of $\mathrm{T}_{4}$ in the thyroid [14]. Further, the basal metabolic rate of newborn calves increases rapidly after birth, attains a peak at 2-4 days after birth, decreases rapidly until 8 days, and thereafter decreases gradually and stabilizes after 21 days [3]. Calves spend the stored thyroid hormone on active energy metabolism just after birth. TSH and secretion of $\mathrm{T}_{4}$ from the thyroid gland are suppressed by the negative feedback system of thyroid function. It is thought that as a consequence, the thyroid hormone levels decrease rapidly from 1 day after birth .

Thyroid hormones have a great variety of effects on the growth of the fetus and newborn calves [1]. Dietary iodine deficiency is associated with stillbirth, abortion, weakness and goiter $[6,11]$. If calves with goiter were to be born on the range during inclement weather, many would die [10]. In this study, many of the calves with goiter were weak and died within 3 days after birth. Serum $\mathrm{T}_{4}$ levels in calves 
with goiter tended to be lower than those of healthy ones, but showed similar levels to those of adult cows. $\mathrm{T}_{3}$ levels of calves with goiter were similar to those of healthy ones, but showed higher variation. From the above results, individual levels of serum $T_{4}$ and $T_{3}$ at just after birth could not be considered as a diagnostic index because of their high variation. However, since the $\mathrm{T}_{4} / \mathrm{T}_{3}$ ratio of calves with goiter was significantly lower than those of healthy ones and adult cows, the $T_{4} / T_{3}$ ratio could be adopted as a diagnostic index of endemic goiter.

\section{REFERENCES}

1. Cabello, G. and Wrutniak, C. 1989. Reprod. Nutr. Dev. 29: 387-402.

2. Davicco, M. J., Vigouroux, E. and Dardillat, C. 1982. Reprod. Nutr. Dev. 22: 355-362.

3. Hernandez, M. V., Kevin, M. E., Reineke, E. P., Oxender, W.D. and Hafs, H.D. 1972. J. Anim. Sci. 34: 780-785.
4. Koneff, A. A., Nichols, C. W. and Wolff, J. Jr. 1949. Endocrinology 45: 242-249.

5. Millar, K. R. and Albyt, A. T. 1985. N. Z. Vet. J. 33: 116-117.

6. Morinaga, Y., Osame, S., Sarashina, T. and Ichijo, S. 1990. J. Vet. Sci. 52: 1309-1311.

7. Nathanielsz, P. W., Silver, M. and Comline, R. S. 1973. J. Endocrinol. 58: 683-684

8. O'Kelly, J. C. and Wallace, A. L. C. 1979. Biol. Neonate. 36: 55-62.

9. Osame, S., Morinaga, Y., Sarashina, T. and Ichijo, S. 1991. J. Jpn. Vet. Med. Assoc. 44: 1198-1101 (in Japanese).

10. Radostits, O. M., Blood, D. C. and Gay, C. C. 1994. Veterinary Medicine, 8th ed. 1395-1398. Bailliere Tindall, London.

11. Seimiya, Y., Oshima, K., Itoh, H., Ogasawara, N., Matsukida, Y. and Yuita, K. 1991. J. Vet. Med. Sci. 53: 989-994.

12. Slebodzinski, A. B.and Cociel, F. 1983. Endocrinol. Exp. 17: 263-270.

13. Strbak, V. and Tomsik, F. 1988. Endocrinol. Exp. 22: 113-116.

14. William, F. G. 2000. Review of Medical Physiology, 19th, ed., Maruzen, Tokyo (in Japanese). 